\title{
El silencio de los órganos. Los desencuentros de la salud y la normalidad según
Ganguilhem y M. Foucault
}

\author{
The silence of organs. \\ Disagreements between health \\ and normality according to \\ G. Canguilhem and M. Foucault
}

\author{
ESTEBAN A. GARCÍA \\ Universidad de Buenos Aires-Consejo Nacional de Investigaciones Cientificas y \\ Técnicas (Argentina)
}

Recibido: 09/08/2012 Aceptado: 12/03/2013

\begin{abstract}
RESUMEN
Este trabajo se propone analizar y confrontar las perspectivas teóricas divergentes de G. Canguilhem y de M. Foucault en torno al estatus epistemológico de las ciencias modernas del cuerpo humano. Ambos filósofos investigaron factores extracientíficos determinantes en la constitución del objeto mismo de la fisiología: aquel cuerpo humano calificado como «normal» que la técnica médica adopta como ideal terapéutico. Sin embargo, Canguilhem apeló en sus análisis a fundamentos subjetivos y biológicos (tales como el padecimiento humano y la «normatividad vital»), mientras que su discípulo otorgó mayor relevancia a los factores políticos de normalización social.
\end{abstract}

PALABRAS CLAVE

NORMALIDAD, MEDICINA, CORPORALIDAD, VIDA

(C) Contrastes. Revista Internacional de Filosofia, vol. XIX-Nº1 (2014), pp. 27-45. ISSN: 1136-4076

Departamento de Filosofía, Universidad de Málaga, Facultad de Filosofía y Letras Campus de Teatinos, E-29071 Málaga (España) 


\begin{abstract}
The aim of this paper is to analyze and confront two diverging theoretical perspectives -those pertaining to G. Canguilhem and M. Foucault-concerning the epistemological status of modern sciences of the human body. Both philosophers examined extra-scientific factors that play a role in the constitution of the object of physiology: the human body qualified as «normal», which medical technique regards as a therapeutic ideal. However, in his analysis Canguilhem referred to subjective and biological foundations (such as human suffering and «vital normativity»), whereas his disciple granted greater importance to the political factors of social normalization.
\end{abstract}

KEYWORDS

NORMALITY, MEDICINE, CORPOREALITY, LIFE

ESTAS PÁGINAS SE PROPONEN RECONSTRUIR un diálogo filosófico en torno al sentido, el origen y el estatus espistemológico de las ciencias modernas del cuerpo humano, entablado a lo largo de más de veinte años entre ciertas obras de G. Canguilhem y su discípulo M. Foucault. Este cruce de ideas, cuyos pormenores fueron frecuentemente desatendidos por los exégetas, atravesó cuanto menos tres momentos resonantes en lo que respecta a la serie de las publicaciones. El Ensayo sobre algunos problemas concernientes a lo normal y lo patológico (1943) de Canguilhem (en adelante referido como Essai) se propuso mostrar que la constitución del objeto mismo de la fisiología moderna -el cuerpo calificado como «normal»- era deudora de la interacción de diversos factores extracientíficos entre los que se contaría, en primera instancia, la técnica médica. Ésta se fundaría y originaría a su vez, según Canguilhem, en una doble fuente: la experiencia subjetiva del padecimiento, por un lado, y la «normatividad» de los procesos biológicos por otro. El análisis de las condiciones extracientíficas de producción del cuerpo-objeto de las ciencias fue retomado veinte años más tarde por M. Foucault desde una perspectiva original con la publicación de $E l$ nacimiento de la clínica (1963), obra que ligaba históricamente el surgimiento de la medicina moderna a determinados procesos políticos de normalización social. Los ecos tardíos y un tanto discordantes de las ideas del maestro en la obra de su discípulo hicieron a su vez que Canguilhem añadiera un desenlace alternativo a su obra previa, integrando el tópico foucaultiano de la normalización a sus anteriores desarrollos en torno a la normalidad fisiológica y la normatividad vital: las «Nuevas reflexiones sobre lo normal y lo patológico» se agregaron a modo de Segunda Parte en la reedición de 1964 del Essai, conformando así la obra que lleva hoy definitivamente el título de Lo normal y lo patológico. Al reconstruir las alternativas teóricas de este diálogo nos preguntaremos si por debajo de esta historia de resonancias y continuidades aparentes entre los desarrollos alternantes de ambos autores no se perpetúan desavenencias filosóficas irreconciliables. Aun si ambos hubieran convenido en ligar internamente 
la fisiología - en virtud de su particular objeto de estudio- con el desarrollo de prácticas y técnicas que desbordan la metodología científica, iimplicaba esto necesariamente para ambos filósofos el que las ciencias modernas del cuerpo -y el cuerpo mismo-se vieran sustancialmente determinados por una azarosa historia de intereses pragmáticos, profesionales y políticos?

\section{LA FENOMENOLOGÍA DE LA SALUD FRENTE A LA FISIOLOGÍA DE LA NORMALIDAD}

En una conferencia dictada en 1988, pocos años antes de su muerte, Canguilhem reivindica el valor de un cierto «concepto vulgar» de la salud. ${ }^{1}$ La calificación de «vulgar» no alude en este caso a lo trivial, sino sólo a algo común o al alcance de todos. No se trata tampoco de un concepto en sentido propio, sino más bien de una noción no enunciada, no reflexiva y precientífica operante de modo tácito en nuestra experiencia: al sentirse sano o enfermo y reconocer la diferencia cada uno de nosotros muestra poseer un saber inmediato acerca de la salud y de la enfermedad. Este saber vulgar es el que refleja una de las máximas más citadas por Canguilhem, atribuida al cirujano Leriche: «la salud es la vida en el silencio de los órganos». ${ }^{2}$ En términos menos metafóricos: en la salud el cuerpo no se ve obligado a sentirse a sí mismo. Estoy sano cuando estoy volcado a mis actividades, atento al mundo e interactuando con los otros sin tener que escuchar a mi cuerpo, sin tener que «atenderme» en el doble sentido de procurarme cuidados y de volver la atención hacia mí mismo. En las penosas ocasiones en que nuestro cuerpo rompe su silencio y oímos «el llamado patético de la vida» no sólo los órganos solicitan nuestra atención, sino que también nosotros reclamamos la atención de los otros y rompemos espontáneamente la discreción de nuestras relaciones sociales: el niño llora reclamando ser atendido por otros y los adultos nos quejamos y eventualmente llamamos o acudimos a un médico. ${ }^{3}$ Por lo general, los médicos en su práctica no sostienen una definición estricta de la salud sino que «al fin y al cabo son los enfermos quienes la mayoría de las veces juzgan -y desde puntos de vista muy diversos- si ya no son normales o si han vuelto a serlo». ${ }^{4}$ En otros casos, sin embargo, el saber del médico acerca del cuerpo de su paciente difiere, se opone e incluso puede pretender imponerse a la vivencia que tiene el afectado de su propio cuerpo. La salud y el padecimiento tal como son subjetivamente vividos no son siempre y exactamente congruentes con los criterios médicos de

1 G. Canguilhem, «La salud: concepto vulgar y cuestión filosófica», en Escritos sobre la medicina, tr. I. Agoff. Buenos Aires-Madrid: Amorrortu, 2004, pp. 49-67.

2 G. Canguilhem, Lo normal y lo patológico, tr. R. Potschart. México: Siglo XXI, 1978, p. 86 .

3 Ibid. p. 174.

4 Ibid. p. 86. 
lo normal y lo patológico, cuestión lo suficientemente curiosa como para que Canguilhem emprenda la investigación de su Tesis de Doctorado en Medicina publicada en 1943 con el título de Ensayo sobre algunos problemas concernientes a lo normal y lo patológico.

La medicina es, en la definición del filósofo, «una técnica terapéutica situada en la encrucijada de muchas ciencias», y aquella ciencia en la que principalmente respalda su autoridad para los profesionales que la ejercen así como para quienes acudimos a ella es la fisiología. ${ }^{5}$ Esta última se define comúnmente como la ciencia que describe las funciones del organismo tal como éste es. Sin embargo, se da por sentado en tal definición el hecho singular de que la descripción corresponde más específicamente a un organismo ya calificado como «normal»: las pulsaciones, la respiración, la temperatura o los componentes sanguíneos tienen ritmos y valores que la fisiología describe en sus rangos «normales» y que son útiles para el diagnóstico médico. Así, la presunta descripción anátomo-fisiológica objetiva del cuerpo «tal como es y funciona» supone siempre tácitamente esta referencia valorativa al cuerpo «tal como debería ser y funcionar» normalmente. Lo «normal», en efecto, alberga una ambigüedad semántica: refiere a la vez a un hecho constatado y un valor propuesto, es una cantidad medible y cuya preeminencia es constatada en cierta población, pero indica a la vez un ideal así como un objetivo, una finalidad o una dirección hacia la que el médico orienta los cuerpos durante la cura. Canguilhem se propone mostrar que su significado fáctico, presuntamente objetivo, no es nunca separable de su significado valorativo: la normalidad fisiológica se funda en una normatividad que permanece por lo general oculta.

El científico del cuerpo puede, por ejemplo, constatar la presencia de un microbio o de formaciones celulares como las que llamamos cancerígenas, puede medir cantidades relativamente típicas o atípicas, pero no es de la aplicación de métodos científico-objetivos que procede la posibilidad de valorar estas cifras o fenómenos como normales o patológicos. Esta valoración o calificación es un préstamo no reconocido, un legado tanto histórico como epistemológico que le ha hecho y le sigue haciendo a la fisiología la clínica terapéutica en su necesidad de atender a quienes primeramente se declaran sufrientes y enfermos. La fisiología no sería entonces, como se aduce, la descripción del cuerpo tal como objetivamente es sino «la colección de las soluciones cuyos problemas han sido planteados por los enfermos mediante sus enfermedades».. ${ }^{6}$ En tanto tiene por objeto el organismo que es llamado «normal»y la normalidad contiene una referencia tácita a un valor vital, el de la salud, Canguilhem concluye que la fisiología es una ciencia en lo que respecta a sus métodos, análogos a los dela

5 Ibid. p. 11.

6 Ibid. p. 70. 
física o la química, pero no respecto de su objeto. Se establece así una serie histórica y epistemológica de fundamentación del sentido de los conceptos científicos: la fisiología se funda en la fisiopatología, la cual se funda en una terapéutica -en nuestra cultura, la clínica médica-que responde a su vez a la experiencia humana del dolor y la enfermedad tal como son vividos: «En materia biológica el pathos es quien condiciona al logos, porque lo requiere. [...] La vida sólo se eleva a la conciencia y a la ciencia de sí misma por [...] el dolor».7

Es hora de precisar la índole de estos términos - tales como la vida y el padecimiento-, aún un tanto oscuros y ciertamente heterogéneos, que funcionan para Canguilhem como fundamentos reprimidos de las ciencias del cuerpo. Por un lado, las referencias a la «experiencia vivida» del padecimiento parecen apelar a un marco de cuño patentemente fenomenológico, aún si las simpatías del epistemólogo por sus contemporáneos lectores de Husserl no fueran reconocidas ni celebradas por sus discípulos. En 1984 Michel Foucault redactó una revisión de su Prefacio para la edición estadounidense de la obra de su maestro Canguilhem, Lo normal y lo patológico. Este texto, que constituiría el último que Foucault enviara a impresión, trazaba un panorama bifaz de la filosofía francesa de la mitad del siglo pasado oponiendo a los filósofos-fenomenólogos de lo vivido y del sentido, entre quienes contaba a Merleau-Ponty, frente a la tradición epistemológica representada por la filosofía del viviente de Canguilhem. ${ }^{8}$ Sin embargo, es claro que los argumentos de Canguilhem hasta este punto resumidos distan de ubicarse en las antípodas de la fenomenología de lo vivido como pretendía Foucault. En cierto sentido, incluso, podrían interpretarse como una derivación posible del proyecto de Husserl de buscar en la doxa de la experiencia y en el Lebenswelt - el mundo de la vida que el fenomenólogo justamente definía como horizonte de metas e intereses o, en términos de Canguilhem, valoraciones- la fuente de sentido de las idealizaciones científicas. ${ }^{9}$ Hallamos igualmente en Canguilhem el análogo de aquel proceso descripto por Husserl mediante el cual la ciencia tiende a separarse de la experiencia en la que se fundó para hacer valer sus idealizaciones derivadas como verdades únicas y primeras: «El fisiólogo tiende a olvidar que una medicina clínica y terapéutica $[. .$.$] ha precedido a la fisiología» y «el médico tiende a olvidar que$ son los enfermos quienes llaman al médico». ${ }^{10}$ En este sentido Canguilhem llega a reconocer explícitamente el valor de la fenomenología merleaupontyana del cuerpo vivido: «La definición de la salud que incluye la referencia de la

7 Ibid. p. 160.

8 M. Foucault, «La vie, l'expérience et la science», en Revue de métaphysique et de morale, 90-1 (janvier-mars 1985), pp. 3-14.

9 Cf. E. Husserl, La crisis de las ciencias europeas y la fenomenología trascendental. Una introducción a la filosofía fenomenológica, tr. E. Tabernig. Barcelona: Ed. Crítica, 1991.

10 G. Canguilhem, op. cit., p. 159. 
vida orgánica al placer y al dolor experimentados como tales, introduce subrepticiamente el concepto de cuerpo subjetivo en la definición de un estado que el discurso médico cree poder describir en tercera persona». ${ }^{11}$ Es situándose explícitamente en la línea de este retorno a la experiencia del cuerpo tal como es vivido que Canguilhem apela a un «retorno a la salud fundadora». ${ }^{12}$ El cuerpo vive su salud sin representársela, y esta salud vivida, a la que el filósofo denomina también «salud libre, no condicionada, no contabilizada» y «salud salvaje», no sólo es vivida sin representación sino que es «no susceptible de representación»: ${ }^{13}$ «esta salud sin idea, a la vez presente y opaca, es sin embargo la que, de hecho y en última instancia, sostiene y valida para mí mismo, y también para el médico en tanto es mi médico, los artificios que la idea del cuerpo, es decir el saber médico, puede sugerir para sustentarla»». ${ }^{14} \mathrm{Sin}$ embargo, esta noción «fenomenológica» de la salud no comporta en el análisis de Canguilhem una función rotundamente crítica respecto de la definición médica de la salud, aquella que remite a la normalidad, sino que mantiene con ella relaciones un tanto más ambiguas: la limita, pero a la vez la funda e incluso justifica su necesidad. Así afirma el filósofo que «el reconocimiento de la salud como verdad del cuerpo en el sentido ontológico no sólo puede sino que debe admitir la presencia, en los bordes, y propiamente, como resguardo, de la verdad en sentido lógico, es decir, de la ciencia. Indudablemente, el cuerpo vivido no es un objeto, pero para el hombre, vivir es también conocer». ${ }^{15}$ Ahora bien: si el cuerpo vivido debe limitar los peligrosos desbordes de un cuerpo objetivado que olvidó sus raíces, ¿cómo podría este último a la vez ser invocado como necesario «resguardo» del primero? ¿En qué sentido podría la experiencia subjetiva reivindicar el valor de la investigación objetiva del cuerpo, como a veces sugiere diplomáticamente Canguilhem, si es a la vez patente que lo limita, como revelaba la primera intuición del epistemólogo? ¿No significa acaso la presencia de este «cuerpo vivido» que Canguilhem pone en primer plano una resistencia indeclinable del cuerpo a su objetivación que conspira contra la posibilidad de determinar una «verdad lógica» del cuerpo?

\section{LA NORMATIVIDAD DE LA VIDA: HACIA UNA NOSLOGÍA FILOSÓFICA}

Para elucidar al menos parcialmente estas oscuridades del argumento de Canguilhem es necesario advertir que los términos relativos a una fenomenología de la salud y la enfermedad se entrelazan subrepticiamente en el desarrollo del Essai

11 G. Canguilhem, Escritos sobre la medicina, p. 63.

12 Ibid. p. 66.

13 Ibid. pp. 61, 62, 66.

14 Ibid. p. 62.

15 Ibid.p. 67 
con conceptos de una índole marcadamente disímil, más propios de una filosofía de la vida y de una nosología filosófica que de una fenomenología. En efecto, aquella máxima que afirmaba que «la salud es la vida en el silencio de los órganos» puede dar pie simultáneamente a dos tipos de reflexión: fenomenológica y ontológica. Por un lado, la frase define la salud como una experiencia subjetivamente vivida y caracterizable como activa, fácil, fluida, cómoda o ininterrumpida. Pero también puede oírse la palabra «vida» ya no fenomenológicamente como la experiencia o vivencia subjetiva sino filosóficamente como aquello que más geneneralmente define e impulsa a todo ser viviente. En este sentido la frase resuena como un eco de aquella sentencia cartesiana que compara la salud con la verdad: «El conocimiento de la verdad es como la salud del alma: una vez que se la posee, no se piensa más en ella». ${ }^{16}$ Así como para Descartes la verdad es la salud del alma, Canguilhem propone pensar la salud como «la verdad del cuerpo». No se trata del tipo de verdad atribuible a una idea o un juicio, una verdad lógica o lingüística, sino de la verdad ontológica del cuerpo: aquella cualidad de la experiencia por la cual algo aparece tal cual es. ${ }^{17}$ Esta verdad o esta salud del cuerpo equivale en la visión de Canguilhem a la auto-organización y auto-regulación propias y singulares de cada especie y de cada ser vivo que le permiten relacionarse provechosamente con sus particulares entornos. La configuración de todo ser vivo es, según Canguilhem, por sí misma «normativa» en un sentido particular, y es esta normatividad vital la que justificaría y fundaría la investigación de la normalidad que realiza el fisiólogo.

Es claro que nos encontramos aquí con términos más propios de una filosofía de la vida que de una fenomenología de la experiencia subjetiva, cuyas relaciones con la fisiología eran menos evidentes. Esta filosofía de la vida expuesta en el Essai de 1943 adopta como una de sus premisas básicas el que «la vida es una actividad normativa» entendiendo aquí por «normativo» aquello que instituye normas, aquello que valora, prefiere y excluye, se acerca o se aleja, incorpora o excreta de acuerdo a lo que conviene específicamente a su propia supervivencia, desarrollo y bienestar orgánico. ${ }^{18}$ La normatividad característica de todo ser vivo es un plus mediante el cual se equilibra el déficit de la fragilidad o precariedad que define a todo lo vivo. Este carácter débil, inestable y poco firme, esta apertura a la muerte y a la enfermedad -término que justamente deriva del latín in-firmitascaracteriza para Canguilhem a los fenómenos vivientes frente a los fenómenos físicos y químicos: «hay una patología biológica, pero no hay patología física o química o mecánica». ${ }^{19}$ Así, todo organismo vivo tiene una organización, un tipo de comportamiento y un espectro de actividades propias que establecen

16 Citada por G. Canguilhem, Escritos sobre la medicina, p. 52.

17 Ibid. p. 53 .

18 G. Canguilhem, Lo normal y lo patológico, p . 92.

19 Ibid. p. 93. 
valoraciones en su entorno como condición de su desarrollo y supervivencia. Se puede hablar de normatividad biológica por cuanto «vivir es, incluso en una ameba, preferir y excluir. Un tubo digestivo, unos órganos sexuales, son normas del comportamiento de un organismo». ${ }^{20}$ De modo semejante, los tejidos espontáneamente cicatrizan y la sangre coagula para mantener esta organización, y los animales muestran conductas higiénicas y terapéuticas. Análogamente, la medicina debería ser comprendida como un recurso más de un ser vivo -en este caso el ser humano- que tiene como finalidad mantener su particular organización, aun si se tratara en este caso de un recurso más sofisticado y conciente que otros recursos naturales.

Se advierte que Canguilhem, por un lado, parece denunciar en la fisiología una presunción científica no suficientemente fundamentada, por cuanto tal disciplina no es solamente el compendio de constataciones fácticas que aduce ser sino que encubre una valoración normativa. Sin embargo y simultáneamente, al ser esta valoración concebida como una expresión y prolongación de la más originaria normatividad vital, al saber fisiológico y a la técnica médica que utiliza sus resultados se les devuelve ahora como contrapartida una legitimación aún más fuerte: mediante la medicina «el ser humano prolonga, de manera más o menos lúcida, un esfuerzo espontáneo propio de la vida por luchar contra aquello que presenta un obstáculo a su persistencia y a su desarrollo considerados como normas». ${ }^{21}$

Sin embargo, ¿puede realizarse sin dificultad este movimiento por el que Canguilhem pretende fundar y derivar la normalidad fisiológica en y desde la normatividad vital? Responder afirmativamente parece difícil por varias razones. En primer lugar, la normatividad vital tal como la define Canguilhem parece diferir de la normalidad fisiológica en la medida en que esta última se refiere a funciones y valores fijos, a ciertos umbrales y límites constantes. Por el contrario, que el viviente sea normativo no significa que se ajuste a normas fijas sino que instituya normas nuevas: el viviente es siempre «prototípico» y no «arquetípico», como afirmaba el mismo Canguilhem. ${ }^{22}$ La normatividad entendida como creación de nuevas normas, variación o diferenciación, es condición de la vida en tanto permite a los organismos adaptarse a diferentes medios o bien a los cambios de un mismo medio. Canguilhem aplica este razonamiento incluso al individuo humano, dando lugar a una definición filosófica original de la salud o la normalidad que difiere de la científica: el hombre normal o sano en el sentido propiamente filosófico propuesto por Canguilhem no es el que se enmarca en

20 Ibid.pp. 94, 95, 101.

21 Ibid. p. 92.

22 G. Canguilhem, «Le normal et le pathologique», en La connaissance de la vie. París: Vrin, 2006, p. 206. 
una norma fisiológica sino «el hombre normativo, el ser capaz de instituir nuevas normas». ${ }^{23}$ Lejos de que el estado patológico o anormal exprese la ausencia de una norma, «la enfermedad es aún una norma de vida, pero [...] que no tolera ninguna desviación, [...] que es incapaz de transformarse en otra norma. El ser vivo enfermo está normalizado en condiciones de existencia definidas y ha perdido la capacidad normativa, la capacidad de instituir diferentes normas en condiciones diferentes.» El cuerpo enfermo «está enfermo porque sólo puede admitir una norma: el enfermo no es anormal por ausencia de norma sino por incapacidad de ser normativo». ${ }^{24}$ En contraste, la salud es definida ahora como «la posibilidad de tolerar infracciones a la norma habitual», «un margen de tolerancia respecto a las infidelidades del medio ambiente»y «un lujo biológico». ${ }^{25}$

Tras introducir estas radicales definiciones en su Essai, Canguilhem parece buscar una difícil reconciliación entre la creatividad de la normatividad biológica y la fijeza de la normalidad fisiológica añadiendo la tesis de que las normas vitales, si bien no pueden derivarse de promedios bioestadísticos, se expresan en tales promedios. ${ }^{26}$ Según el filósofo, la pretensión de definir valores fisiológicos «normales», fijos y universales mediante el establecimiento de promedios por métodos biométricos o, tal como actualmente se denominan, «bioestadísticos», encuentra más de un obstáculo insuperable. El cálculo de un promedio anatómico o fisiológico (e.g., el peso o el ritmo cardíaco) no es el de un promedio aritmético donde se suman los términos y se divide el total por el número de sumandos. Un promedio aritmético puede no representar siquiera remotamente las características de ningún individuo existente, mientras que los promedios anátomo-fisiológicos se sirven de otros tipos de mediciones que relevan una mayoría de individuos realmente existente que comparten ciertos valores o rasgos. El promedio bioestadístico surge directamente del censo de una población y se manifiesta gráficamente por sí solo como una meseta más o menos aparente en la tabla de doble entrada. Ahora bien, la determinación de este promedio no reviste la misma exactitud que el primero. En primer lugar, es notorio que los métodos bioestadísticos no pueden determinar matemáticamente el corte alrededor del valor promedio o «normal», el cual siempre será en cierto grado arbitrario. En segundo lugar, si bien pueden determinarse promedios relativos a grupos poblacionales determinados, «la objetividad se desvanece totalmente en la determinación de una normalidad global» ${ }^{27}$ debido a las enormes variaciones históricas y geográficas que presenta la especie humana: basta pensar en la

23 G. Canguilhem, Lo normal y lo patológico, p. 104.

24 Ibid. p. 141.

25 Ibid. p. 151.

26 Cf. ibid., Parte II, cap. 3: «Norma y promedio».

27 Ibid. p. 116.

Contrastes vol. XIX-Nº1 (2014) 
diversidad de la duración promedio de la vida humana a lo largo de la historia o en distintas naciones en el presente para percatarse de que un promedio no puede definir valores «normales» en el sentido de universales, fijos o propios de una fisiología humana natural.

Ahora bien, es sin embargo un dato irrefutable y curioso el que la distribución de los valores de una variable anatómica o fisiológica siempre adopta una forma acampanada (una «curva de Gauss») en las tablas de doble entrada. Desde las primeras investigaciones biométricas se observó que la mayor cantidad de individuos de hecho parece acomodarse a valores compartidos -aquellos que identificamos como nuestros valores «promedio» $\mathrm{y}$ «normales»- $\mathrm{y}$ las desviaciones son tanto más excepcionales cuanto más pronunciadas. Dicho de otro modo: si por las razones antes observadas resulta difícil deducir una «normalidad objetiva» a partir de la determinación de promedios, en cambio es patente que los promedios constatables expresan una cierta «normalidad normativa» que los rige. Sin embargo, si todo indica que una norma o un ideal valorado orienta esta distribución acampanada de cierta variable en cierta población, esta norma no puede ser, como de hecho supusieron los primeros estadistas, la propia de una naturaleza humana instituida por Dios, ya que el alcance más amplio de las mediciones contemporáneas desafía una universalidad tal. La aguda respuesta que Canguilhem otorga a este dilema es que, si bien un rasgo humano no es frecuente por ser «normal» en el sentido de una constante fisiológica universal, sí lo es por ser «normal» en el sentido de «normativo» para o valorado por un determinado grupo poblacional con un determinado género de vida: «Las normas fisiológicas definen no tanto una naturaleza humana como hábitos humanos relacionados con géneros de vida, niveles de vida y ritmos de vida»; «las constantes funcionales son normas habituales» propias de cada sociedad. ${ }^{28}$ Los valores promedio de las constantes fisiológicas humanas son, en términos del filósofo, «expresión de normas colectivas de vida»: «la especie humana al inventar géneros de vida inventa al mismo tiempo modos de andar fisiológicos»». ${ }^{29}$ Así, los distintos modos de vida y correlativas constantes fisiológicas propias de cada cultura serían expresiones de la creatividad y diversificación vital del género humano -su «normatividad»- para adaptarse a distintos medios. La fisiología es definida por el filósofo al culminar su Essai como la «ciencia de los modos de andar estabilizados de la vida». Se le asigna así un peculiar objeto «cuya identidad consigo mismo es la de un hábito antes que la de una naturaleza, pero cuya constancia relativa es quizá más precisamente adecuada» a los fenómenos de los que se ocupa. ${ }^{30}$

28 Ibid. pp. 127, 129.

29 Ibid. p. 132.

30 Ibid. p. 157.

Contrastes vol. XIX-No1 (2014) 


\section{NORMALIDAD MÉDICA, NORMATIVIDAD VITAL Y NORMALIZACIÓN SOCIAL}

En su intento de preservar cierta legitimidad epistemológica de la fisiología y cierto valor a la praxis médica fundando a ambas en la normatividad vital, la solución de Canguilhem parece traicionar la originalidad de este último concepto tal como había sido caracterizado previamente. Canguilhem priorizaba el carácter creativo, desbordante y diversificador del proceso vital por sobre las explicaciones biológicas adaptativas. Sin embargo, al promediar su Essai la vida parece a fin de cuentas crear normas nuevas y diferentes solamente para adaptarse a nuevos medios, y las constantes normales fisiológicas adquieren la apariencia de galardones que coronan a cada adaptación eventualmente vencedora. En ciertos pasajes previos de su Essai Canguilhem se había mostrado muy conciente de que las explicaciones adaptativas del proceso vital son siempre deficitarias, y que la normatividad de la vida desborda una explicación adaptacionista: la vida no diversifica sus formas para adaptarse a un medio sino que lo hace a despecho del medio, excediendo la necesidad, derrochando caprichosamente variedades con la osadía característica de las creaciones artísticas. ${ }^{31}$ El carácter vital es esencialmente excesivo y desbordante, así como la buena salud no es la adaptada a ciertos márgenes normales sino una salud «rebosante» que puede abusar de sí misma.

Este carácter arbitrario que adopta la normatividad vital se exacerba y reviste características únicas en el caso particular del viviente humano. En varios pasajes de su Essai Canguilhem se muestra conciente de los nuevos factores que entran en juego cuando se considera que el medio al que debe adaptarse el humano no es en ningún caso un medio «natural» sino un medio también humano o transformado por el hombre. Es útil reproducir in extenso uno de los más párrafos significativos y elocuentes en este sentido: «finalmente, en ese número abstracto que es la duración promedio de la vida humana, está expresado un juicio de valor. La duración promedio de vida no es la duración de vida biológicamente normal, sino que en cierto sentido es la duración de vida socialmente normativa. También en este caso, la norma no se deduce del promedio sino que se traduce en él». Esto sería aún más claro, agrega, «si en lugar de considerar la duración promedio de vida en una sociedad nacional tomada en bloque, se especificase esa sociedad en clases, oficios, etc»r. ${ }^{32}$ La normalidad de las sociedades humanas es entonces efectivamente normativa, pero claramente no expresa aquella normatividad vital que admira Canguilhem, ni en la acepción más adaptativa ni en la más creativa del concepto: los diferentes promedios de duración de vida que se constatan en estratos poblacionales que difieren económicamente $u$ ocupacionalmente, por ejemplo, no remiten a la adaptación a cierto medio dado, ni son tampoco meras

31 Para una crítica de la tendencia a la conservación (frente a la expansión) como ley general de la vida $c f$. ibid., Parte II, cap. 4.

32 G. Canguilhem, Lo normal y lo patológico, p. 121.

Contrastes vol. XIX-Nº1 (2014) 
expresiones pintorescas de la idiosincracia o la singularidad características de una sociedad. Ellos expresan los valores de sectores sociales determinados que, en pugna con otros, han conseguido imponerse. El promedio normal de vida de un minero expresa una normatividad, pero no vital ni tan siquiera social o nacional en general, sino específicamente burguesa, terrateniente o patronal. En la medida en que esta normalidad depende de agentes sociales en conflicto, expresa una normatividad que concierne a agentes políticos, económicos, morales, etc. que cumplen funciones «normalizadoras». La clínica médica no se guía por estos promedios específicos o sectoriales sino que utiliza los mismos estándares para cualquier miembro de una sociedad dada, tomando en cuenta en cambio las diferencias más globales entre distintas sociedades en función de variables climáticas, alimentarias, genéticas, etc. Posiblemente por ello Canguilhem puede ver la normalidad fisiológica como la mera expresión de una normatividad vital: las sociedades humanas se presentan a esta luz como una profusión selvática de especies botánicas curiosas, coloridas, multiformes y exóticas. El ensayo de Canguilhem, que comenzaba criticando el alcance y las pretensiones de la medicina y la fisiología desde el cuerpo vivido como su fundamento y origen reprimido, va desdibujando de a poco los contornos más ásperos del cuerpo vivido hasta metamorfosearlo en la más armónica figura de la vida misma y su normatividad, diluyendo y limitando de ese modo el cariz crítico de su argumento.

Paradójicamente, quizá sea Foucault -quien se declaraba en las antípodas de la filosofía de lo vivido y en la línea de la filosofía canguilhemiana del viviente- el encargado de retomar inadvertidamente la resistencia del cuerpo vivido frente a las prácticas y los saberes modernos del cuerpo, rebelión que latía en los pasajes mas críticos del Essai. Puesto que los análisis históricos de Foucault, más allá de la erudición historiográfica y los intereses epistemológicos, no persiguieron en última instancia otro objetivo que el de revelar la genealogía insospechada, azarosa y brutal de nuestro presente y nuestra cotidianeidad: desarrollar «una historia de los cuerpos y de la manera en que se invadió lo que tienen de más material y viviente». ${ }^{33}$ Es por ello que, aún evadiendo las referencias al cuerpo vivido o al pathos características de su maestro, pudo mostrarse más sensible a ciertos aspectos concretos de la enfermedad y el tratamiento por todos conocidos. Si el médico (y la medicina) parecen en los análisis de Canguilhem surgir de la demanda del enfermo y responder a ella, Foucault se pregunta por qué en nuestros días la presencia de la medicina desborda la demanda de la enfermedad y los médicos nos aconsejan en los medios masivos de comunicación acerca de nuestra alimentación y nuestra vida sexual, o peritan en los tribunales de justicia.

33 M. Foucault, Historia de la Sexualidad I: La voluntad de saber, tr. U. Guiñazú. Buenos Aires: Siglo XXI, 1990, p. 184. 
Se pregunta además por las dimensiones políticas y económicas constitutivas de la práctica médica contemporánea que hacen que, a la inversa, los médicos no sean fácilmente asequibles justamente en la circunstancia en que deberían estar presentes (i.e., en respuesta a la demanda de los enfermos ${ }^{34}$ ). Cuando Foucault analiza el nacimiento de la clínica no se refiere meramente a la historia de un espacio, una institución o un método: se trata esencialmente de desentrañar el sentido de la clínica como aquella situación pautada y repetida pero siempre curiosa en que mi cuerpo se encuentra frente a frente con «la mirada médica», un encuentro en el que el mismo Canguilhem había vislumbrado ribetes agonísticos. El argumento epistemológico principal del Essai acerca de la relación fundacional entre la normatividad vital, la praxis médica y la normalidad fisiológica parece adolescer de serias deficiencias a esta luz y necesitaría ser radicalmente reformulado para hacer justicia a estas nuevas variables del análisis. Al suponer que la normalidad es una categoría científica y no reconocer su cariz valorativo, la mirada médica puede universalizar y naturalizar las valoraciones de los agentes sociales en cada caso más poderosos: el saber fisiológico y la técnica médica adquieren así funciones «normalizadoras» como las que pone de relieve Foucault en El nacimiento de la clínica (1963), funciones para las que el mismo Canguilhem reservará el término de «normalización» en sus Nuevas reflexiones concernientes a lo normal y lo patológico, anexadas en 1966 -tras la publicación de la obra de Foucault- como una segunda parte a su ensayo.

En El nacimiento de la clínica Foucault pretende mostrar que la medicina, desde principios del siglo XIX cuando adopta los motivos profesionales, hospitalarios y clínicos que la caracterizan hasta hoy, no es sólo «el corpus de técnicas de curación y el saber que éstas requieren» sino que abarca también «un conocimiento del hombre saludable», «una definición del hombre modelo. En la gestión de la experiencia humana toma una postura normativa [...] que la autoriza a dirigir las relaciones físicas y morales del individuo y de la sociedad donde vive». ${ }^{35}$ Foucault concentra su análisis en el giro histórico que inaugura la medicina moderna a fines del siglo XVIII y afirma que sólo desde entonces la enfermedad se empieza a definir a partir del par conceptual de lo normal y lo patológico. ${ }^{36}$ Este es el momento en que la enfermedad adquiere la apariencia privilegiada de la epidemia, institucionalizándose un sistema de vigilancia jerarquizado y organizado regionalmente de medicina de las epidemias con el refuerzo de una policía que controla los emplazamientos de cementerios, los

$34 C f$. a estos respectos M. Foucault, «La crisis de la medicina o la crisis de la antimedicina», en La vida de los hombres infames. Buenos Aires: Altamira, 1996, pp. 68 ss.

35 M. Foucault, El nacimiento de la clínica. Una arqueología de la mirada médica, tr. F. Perujo. México: Siglo XXI, p. 35.

36 Ibid. p. 61.

Contrastes vol. XIX-Nº 1 (2014) 
alimentos y la salubridad de los lugares públicos: aparecen así, por ejemplo, inspectores y reglamentos de salud para leerse en la misa. En este contexto surge asimismo en Francia la Real Sociedad de Medicina (1776) en conflicto con la Facultad y «el tema de la Enciclopedia deja su puesto al de una información constante y constantemente revisada»: «A la estructura plana de la medicina clasificadora sigue una gran figura esférica en que el espacio médico puede coincidir con el espacio social o lo atraviesa enteramente. Se comienza a concebir una presencia generalizada de médicos cuyas miradas cruzadas forman una red de vigilancia constante, móvil, diferenciada». ${ }^{37}$

Como si no bastara la implantación de los médicos, agrega Foucault, «se pide que la conciencia de cada individuo esté médicamente alerta; [...] que cada ciudadano esté informado». ${ }^{38}$ A comienzos de la Revolución Francesa nace «el mito de una profesión médica nacionalizada, organizada a la manera del clero e investida, en el nivel de la salud y del cuerpo, de poderes parecidos a los que éste ejerce sobre las almas». ${ }^{39}$ Los médicos aparecen, a esta luz, como una suerte de sacerdotes del cuerpo y la medicina como el calco laico de la Iglesia. En un momento histórico en que se imagina la desaparición social de la enfermedad en una sociedad sin guerras la primera tarea del médico es política: curar es a la vez liberar. ${ }^{40}$ Este mito de los primeros revolucionarios desaparecerá pronto, pero «ha tenido un papel importante vinculando la medicina a los destinos de los Estados», otorgándole una función e intervención positiva que desborda el mero análisis y curación de enfermedades: la medicina «recibe la hermosa tarea de instaurar en la vida de los hombres las figuras positivas de la salud, de la virtud y de la felicidad; toca a ella escandir el trabajo para las fiestas, exaltar las pasiones tranquilas; velar sobre las lecturas y la honestidad de los espectáculos; tiene también que controlar que los matrimonios [...] estén bien fundados» ${ }^{41}$ En la gestión de la existencia humana la medicina toma una postura normativa, situándose «en esta zona marginal, pero, para el hombre moderno, soberana, en la cual una cierta felicidad orgánica, lisa, sin pasión y musculosa, comunica en pleno derecho con el orden de una nación, el vigor de sus ejércitos, la fecundidad de su pueblo y la marcha paciente de su trabajo». ${ }^{42}$ Es solamente en esta coyuntura histórica, según Foucault, que la categoría de lo normal que permanecía implícita en el pensamiento médico aparece en pleno relieve y se torna «el corazón mismo de toda reflexión médica». ${ }^{43}$

37 Ibid. pp. 52, 55.

38 Ibid. p. 56.

39 Idem.

40 Ibid. pp. 57, 59.

41 Ibid. p. 61.

42 Idem.

43 Idem. 
Foucault sugiere además que el rol de modelo que jugaron las ciencias de la vida en el siglo XIX para las ciencias del hombre no está vinculado primitivamente al carácter comprensivo y transferible de los conceptos biológicos, sino más bien al hecho de que estos conceptos estaban dispuestos en un espacio cuya estructura profunda respondería a la oposición de lo sano y de lo mórbido: «Cuando se hable de la vida de los grupos y de las sociedades, de la vida de la raza o incluso de la vida psicológica, no se pensará en principio en la estructura interna del ser organizado, sino en la bipolaridad médica de lo normal y de lo patológico». Si las ciencias del hombre aparecieron como un «prolongamiento natural de las ciencias de la vida, no es porque ellas estaban biológicamente subtensas, sino médicamente: se encuentra en su estructura de origen una reflexión sobre el hombre enfermo, y no sobre la vida en general»». ${ }^{44}$ Esto significaría, en suma, que ciertos procesos políticos dieron forma a los conceptos bipolares, la metodología y la profesión médica moderna, y su vocación normativa jugó subrepticiamente un rol paradigmático tanto en las modernas ciencias biológicas como en la conformación de las ciencias humanas.

¿En qué medida son conciliables estos análisis históricos con las tesis del Essai de Canguilhem? En un trabajo minucioso y lúcido, Pierre Macherey ha observado que si ambos filósofos desarrollan una crítica a la pretensión de objetividad del positivismo biológico, ésta es efectuada por Canguilhem desde «la experiencia concreta del viviente, $[. .$.$] abriendo una perspectiva que podría$ denominarse fenomenológica sobre el juego de las normas», mientras que la crítica foucaultiana se separa de la consideración de este origen fenomenológico para substituirlo por una arqueología histórica de las normas de la institución medica. ${ }^{45}$ A pesar de advertir este contraste, Macherey considera que en las «Nouvelles réflexions concernant le normal et le pathologique» anexadas en 1966 Canguilhem integra los aportes foucaultianos y admite que el proyecto de fundar filosóficamente la norma fisiológica en la normatividad vital se ve limitado si no socavado una vez que se atiende a los procesos de normalización social. De acuerdo a esta interpretación de la evolución del pensar de Canguilhem, la suspicacia que el filósofo compartía con Foucault respecto de las ciencias humanas y en particular la psicología como pseudo-ciencias cuyo perfil moderno respondería a la lógica de los poderes más que a la de los saberes mismos, se habría extendido ahora al ámbito de las ciencias de la vida y del cuerpo. ${ }^{46}$ Las reflexiones de uno y otro pensador habrían así entablado

44 Ibid. p. 62.

45 P. Macherey, « De Canguilhem à Canguilhem en passant par Foucault », en AA.VV., Georges Canguilhem, philosophe et historien des sciences (Actes du Colloque 1990). París: Albin-Michel, 1993, pp. 286-294.

46 G. Canguilhem, «Qu'est-ce que la psychologie?», en Revue de Métaphysique et de Morale, 1 (Enero-Marzo 1958), pp. 12-31. 
un diálogo armónico y de mutuo enriquecimiento. Sin embargo, ¿muestran las «nuevas reflexiones» de Canguilhem tal receptividad y continuidad respecto de las tesis de Foucault?

En el ensayo titulado «De lo social a lo vital» que inaugura sus «Nouvelles réflexions ...», Canguilhem subraya las diferencias entre la normalidad en su acepción biológica y la normalidad humana y social: la normalidad orgánica sería intrínseca al objeto mientras que lo normal antropológico derivaría de una normalizacion y sería efecto de una elección exterior al objeto calificado como tal. Canguilhem considera la posibilidad de relativizar este contraste: la normalización de los medios técnicos, de la educación, de la salud, de los transportes de personas y mercaderías puede ser vista, en efecto, como la expresión de exigencias colectivas cuyo conjunto define en un sociedad histórica dada su manera de referir su estructura a lo que considera que es su bien propio. ${ }^{47}$ Sin embargo, esta apariencia de «naturalidad» o «inherencia» de tales normas a tales sociedades es producto de que las decisiones normativas que fijan lo normal se enmarcan en el contexto de otras normas, y en definitiva, de una política general que les da coherencia. La correlatividad de las normas en el interior de un sistema social convierte ese sistema en una organización, pero una organización no puede ser equiparada a un organismo: las reglas de una organización tienen que ser representadas, aprendidas, aplicadas y rememoradas mientras que el orden vital está constituido por un conjunto de reglas vividas espontáneamente y sin problemas. ${ }^{48}$ Para ilustrar esta tesis Canguilhem se refiere justamente al momento histórico analizado por Foucault en su Nacimiento de la clínica, cuando en Francia surgen simultáneamente cuerpos de normas técnicas, jurídicas, gramaticales e higiénicas: «entre 1759, fecha de aparición de la palabra normal y 1834 , fecha de aparición de la palabra normalidad, una clase normativa conquistó el poder de identificar-hermoso ejemplo de ilusión ideológica- la función de las normas sociales con el uso que ella misma hacía de aquellas cuyo contenido determinaba»». ${ }^{49}$

Esta anexión del tópico de la normalización podría dar pie a la interpretación apresurada de que Canguilhem habría rectificado sus tesis previas a la luz de los análisis foucaultianos: la determinación de la normalidad fisiológica no se pretendería ya fundada en una normatividad vital sino en la normalización social. Sin embargo, si bien todo el ensayo de Canguilhem se empeña en perpetuar cierta ambigüedad retórica que parece acercarlo a las tesis de su alumno - confundiendo así incluso a lectores tan sagaces como Macherey-los conceptos vertidos son no sólo diferentes sino francamente inconciliables. La

47 G. Canguilhem, Lo normal y lo patológico, p. 186.

48 Ibid. p. 197.

49 Ibid. p. 193.

Contrastes vol. XIX-Nº1 (2014) 
principal ambigüedad de la que se saca provecho es la propia de la definición de la normatividad humana en su contraste con la normatividad biológica: ¿abarca la primera, además de la gramática, la técnica, las políticas higiénicas o las leyes, a los cuerpos humanos mismos y a las ciencias que los describen? Es decir, ¿son los cuerpos humanos también normalizados socialmente y políticamente o poseen ellos en cambio normas biológicas inherentemente propias y opacas a tales interferencias? Un solo ejemplo de las «Nuevas reflexiones ...» puede bastar para responder esta pregunta: al distinguir la normalidad biológica de la social, Canguilhem menciona como ejemplo de la primera el peso normal del humano según la fisiología. Si Canguilhem integra en estas nuevas reflexiones la cuestión de la normalización social tratada por Foucault, entonces, solamente lo hace para dejar establecido claramente que la fisiología -en el doble sentido de la ciencia y del cuerpo mismo que es su objeto- permanece en su núcleo fuera de su alcance en vez de estar enteramente atravesada por ella como en el análisis foucaultiano. El anexo de Canguilhem persigue el objetivo explícito de criticar la ilícita aplicación de modelos organicistas a la organización social humana, pero por debajo de este argumento se cuela otro: el que diferencia las ciencias de la vida y del cuerpo, relativas a normas biológicas y fisiológicas «naturales», de otros saberes y técnicas humanas atinentes a normas «culturales», arbitrarias, idiosincráticas y deudoras de vaivenes políticos.

\section{CONSIDERACIONES FINALES}

Por debajo de la apariencia de un diálogo teórico condescendiente entre el maestro y su alumno, laten así desacuerdos filosóficos profundos e irreconciliables. También Foucault disfrazó en una retórica rebuscada su visión francamente destructiva de las tesis centrales expuestas por Canguilhem en su Essai. Como pudimos advertir, La naissance de la clinique apunta a mostrar que todo el argumento de Canguilhem que fundaba la fisiología en la clínica y a ésta en una concepción de la vida amenazada por la muerte, surgió a fines del siglo XVIII en el seno de una determinada coyuntura social y política de «normalización». El diálogo entre ambos puntos de vista nunca pudo avanzar más allá de la formulación de estas diferencias basales. Canguilhem, por su parte, mantuvo su respeto por el conocimiento médico y científico a resguardo de las sospechas políticas que los análisis de Foucault -e incluso, en ocasiones, sus propios análisis- parecían indicar. En sus desarrollos de la década de 1970 acerca de la noción de «ideología científica» (Idéologie et rationalité dans l'histoire des sciences de la vie) criticó de manera explícita la tesis -fácilmente asociable con el derrotero teórico foucaultiano-de que «el juicio de estos saberes [científicos] en cuanto a sus relaciones con sus condiciones de producción atañe de hecho y de derecho a la teoría de la práctica política». De adoptar 
esta tesis, según Canguilhem, «la pretensión de una intersección vertical de la ciencia por la epistemología debe[ría] caer. Pero nos preguntaremos antes si es posible conservar el nombre de ciencia a un género de producciones cuya vertical de corte $[. .$.$] es la política, sustituyendo a la antigua polaridad de lo$ verdadero y de lo falso la nueva polaridad de la conformidad y la desviación por relación a una línea». ${ }^{50}$ Expresado en términos más simples y rotundos: para Canguilhem el estudio de las condiciones de producción del saber científico compete propiamente y en última instancia a la epistemología como análisis filosófico de la lógica que articula los conceptos de una ciencia, y no a una teoría o historia políticas. La fisiología, en consecuencia, conserva un núcleo impenetrable por la historia política, excepto que se renuncie absolutamente a su carácter científíco -algo que Canguilhem nunca pretendió hacer-. Esta posición es reafirmada en su artículo acerca de «Las enfermedades» («Les maladies») publicado en 1989 en la Enciclopedia Filosófica Universal. Allí observa cautelosamente que los intereses - «en todos los sentidos del término»- de las sociedades industriales en la salud de las poblaciones obreras promovió la organización de los hospitales y configuró un nuevo enfoque estadístico y desindividualizado de la enfermedad. Sin embargo -continúa diciendo- estos son «componentes sociales y políticos» que participaron en la invención de «prácticas teóricas actualmente eficaces para el conocimiento de las enfermedades». ${ }^{51}$ Incluso si pudiera haber causalidades sociológicas en la aparición y el curso de las enfermedades -en el sentido en que se habla por ejemplo de «enfermedades del capitalismo»-Canguilhem considera «abusivo confundir la génesis social de las enfermedades con las enfermedades mismas. La úlcera de estómago o la tuberculosis pulmonar son enfermedades cuyo cuadro clínico ignora que pueden ser producto de situaciones de desamparo individual o colectivo». ${ }^{52}$ Este respeto por el cuadro clínico, que se muestra en última instancia impermeable a toda variable social o cultural, deriva del estatuto filosófico-biológico que otorga Canguilhem a la enfermedad como revelación de la infirmitas del viviente: «las enfermedades son los instrumentos de la vida mediante los cuales el viviente, tratándose del hombre, se ve obligado a confesarse mortal». ${ }^{53}$ La noción de enfermedad logra pasar directamente así, en la reflexión de Canguilhem, desde una filosofía de la vida a la medicina y la fisiología, apenas rozando la historia política.

50 G. Canguilhem, Idéologie et rationalité dans l'histoire des sciences de la vie. París: Vrin, 2000, p. 28.

51 G. Canguilhem, «Las enfermedades», en Escritos sobre la medicina, p. 41

52 Ibid.p. 42

53 Ibid. p. 47. 
Esteban García es Licenciado (1998) y Doctor en Filosofía (2005) por la Universidad de Buenos Aires. Actualmente es docente en la cátedra de Gnoseología de la carrera de Filosofía de la misma Universidad, e Investigador Asistente en el Consejo Nacional de Investigaciones Científicas y Técnicas. Asimismo, oficia como director de un proyecto de investigación grupal (UBACYT) radicado en la U.B.A. acerca de fenomenología del cuerpo.

\section{Línea de investigación}

El pensamiento de M. Merleau-Ponty, la fenomenología y la cuestión de la corporalidad en la filosofía francesa contemporánea.

Publicaciones recientes

(2012) Filosofia, corporalidad y percepción, Buenos Aires, Editorial Rhesis, 2012 (ISBN 978-987-27375-1-1).

(2012) Merleau-Ponty en la reflexión contemporánea acerca de las políticas normativas del cuerpo (G. Canguilhem, S. de Beauvoir, M. Foucault, P. Bourdieu, J. Butler) en Mario Teodoro Ramírez et al. (eds.), Merleau-Ponty Viviente, Madrid, Ed. Anthropos, 2012, 574 pp. (ISBN 9788415260226).

Dirección electrónica: baneste72@gtmail.com 
